\title{
Спектрометры с анализаторами МАЭС на основе новых линеек фотодетекторов
}

\author{
*B.A. Лабусов ${ }^{1,2,3}$, А.В. Бехтерев" ${ }^{2}$ В.Г. Гаранин ${ }^{2}$ \\ ${ }^{1}$ Институт автоматики и электрометрии СО РАН, \\ Российская Федерация, 630090, г. Новосибирск, пр. Ак. Коптюга, д. 1 \\ ${ }^{2} \mathrm{OOO}$ «ВМК-Оптоэлектроника», Российская Федерация, 630090, г. Новосибирск, пр. Ак. Коптюга, д. 1 \\ ${ }^{3}$ Новосибирский государственный технический университет, \\ Российская Федерация, 630073, г. Новосибирск, пр. К. Маркса, д. 20
}

*Адрес для переписки: Лабусов Владимир Александрович, E-mail: labusov@vmk.ru

Поступила в редакцию 16 сентября 2021 г., после доработки - 22 сентября 2021 г.

Многоканальные анализаторы эмиссионных спектров (МАЭС) работают в составе более шести сотен комплексов атомно-эмиссионного спектрального анализа на предприятиях России и стран СНГ. До недавнего времени в составе анализаторов МАЭС использовались только линейки фотодиодов БЛПП-369M1, характеристики которых были и остаются достаточными для решения задач интегральной атомно-эмиссионной спектрометрии с использованием ярких источников возбуждения спектров, например, на основе дугового или искрового электрического разряда. Для решения задач, где требуются высокая временная и пространственная разрешающая способность, а также высокая чувствительность, созданы быстродействующие анализаторы МАЭС на основе двух новых линеек фотодетекторов БЛПП-2000 и БЛПП-4000. На их основе разработан и освоен в производстве предприятием «ВМК-Оптоэлектроника» ряд оптических спектрометров:

Атомно-эмиссионные спектрометры:

а. с дуговым и искровым разрядом «Гранд-Глобула» и «Экспресс» для прямого анализа порошковых проб методом испарения из канала графритового электрода, а также металлов;

b. с дуговым разрядом «Гранд-Поток» для экспресс-анализа порошковых проб методом просыпки-вдувания;

с. вакуумные спектрометры с искровым разрядом в атмосфере аргона «Гранд-Эксперт» и «Фаворит» для экспресс-анализа металлов и сплавов;

d. с азотной микроволновой плазмой «Гранд-СВЧ» и с аргоновой индуктивно связанной плазмой «Гранд-ИСП» для анализа жидкостей;

е. с воздушной микроволновой плазмой «Колибри-СВЧ» и с фотометрией пламени «Павлин» для определения щелочных и щелочноземельных элементов в растворах.

Атомно-абсорбционные спектрометры «Гранд-ААС» высокого спектрального разрешения с источником непрерывного спектра и электротермическим атомизатором для одновременного определения элементов в жидкости.

Ключевые слова: оптическая спектрометрия, атомно-эмиссионный, атомно-абсорбционный, спектрометр, анализатор спектров, МАЭС, линейка фотодетекторов, одновременное определение элементов.

For citation: Analitika i kontrol' [Analytics and Control], 2021, vol. 25, no. 4, pp. 262-272

DOI: 10.15826/analitika.2021.25.4.002

\section{Spectrometers with MAES analyzers based on new photodetector arrays}

\author{
*V.A. Labusov'1,2,3, A.V. Behterev2', V.G. Garanin' \\ ${ }^{1}$ Institute of Automation and Electrometry, Siberian Branch of the Russian Academy of Sciences, \\ pr. Akademika Koptyuga, 1, Novosibirsk, 630090, Russian Federation \\ ${ }^{2}$ VMK-Optoelektronika, pr. Akademika Koptyuga, 1, Novosibirsk, 630090, Russian Federation \\ ${ }^{3}$ Novosibirsk State Technical University, \\ pr. K. Marksa, 20, Novosibirsk, 30073, Russian Federation
}


Multichannel analyzers of emission spectra (MAES) are operated as part of more than six hundred systems for atomic emission spectral analysis at enterprises in Russia, the CIS countries, and others. Until recently, MAES analyzers used only BLPP-369M1 photodetector arrays, whose performance is sufficient for integral atomic emission spectrometry applications using bright sources of spectral excitation based, for example, on an arc or spark electric discharge. To solve problems where high temporal spatial resolution and high sensitivity are required, high-speed MAES analyzers have been developed based on two new photodetector arrays-BLPP-2000 and BLPP-4000. A number of optical spectrometers based on these arrays have been developed and put into production by the VMK-Optoelektronika company:

Atomic emission spectrometers:

a. Grand Globula and Ekspress arc and spark spectrometers for the direct analysis of powders by evaporation from the channel of a graphite electrode and for the analysis of metals;

b. Grand-Potok arc spectrometers for the rapid analysis of powders by the spill-injection method;

c. Grand-Ekspert and Favorit argon-spark vacuum spectrometers for the rapid analysis of metals and alloys;

d. Grand-SVCh microwave-induced nitrogen plasma spectrometers and Grand-ISP inductively-coupled argon plasma spectrometers for the analysis of liquids;

e. Kolibri-SVCh microwave-induced air plasma spectrometers and Pavlin flame atomic emission spectrometers for the determination of alkaline and alkaline earth elements in solutions.

Grand-AAS high-resolution continuous-source electrothermal atomic absorption spectrometers for the simultaneous determination of elements in liquids.

Keywords: Optical spectrometry, atomic emission, atomic absorption, spectrometer, spectrum analyzer, MAES, photodetector arrays, simultaneous determination of elements.

\section{ВВЕДЕНИЕ}

Атомно-эмиссионная спектрометрия (АЭС) в настоящее время - один из наиболее информативных многоэлементных методов химического анализа веществ и материалов. Таким он стал благодаря использованию систем регистрации спектров на основе линеек и матриц фотодетекторов. Свой вклад в развитие АЭС внесли и многоканальные анализаторы эмиссионных спектров (МАЭС) [1], которые работают в составе более шести сотен спектральных комплексов АЭС на предприятиях России и стран $\mathrm{CHГ}[2,3]$. Эти спектральные комплексы с МАЭС в основном реализуют способ интегральной АЭС, в которой определение элементов проводится по интегральному спектру, зарегистрированному за один прожиг пробы и содержащий десятки тысяч отчётов по длине волны.

До недавнего времени в составе анализаторов МАЭС использовались только линейки фотодиодов БЛПП-369M1, характеристики которых были и остаются достаточными для решения задач интегральной АЭС с использованием ярких источников возбуждения спектров, например, на основе дугового или искрового электрического разряда. В интегральной АЭС можно управлять интенсивностью спектральных линий в зарегистрированном спектре, а значит - чувствительностью, с помощью изменения базового времени экспозиции благодаря их линейной зависимости друг от друга. Значения базового времени экспозиции в интегральной АЭС обычно составляет 100-250 мс для линеек БЛПП-369M1.

Однако при решении задач сцинтилляционной АЭС (САЭС) было показано, что для получения минимальных пределов обнаружения благородных металлов (БМ) этим способом необходимо регистрировать временнуेю последовательность спектров с временем базовой экспозиции близким длительности вспышек аналитических линий БМ, составляющим единицы миллисекунд $[4,5]$. Такое низкое время базовой экспозиции и отсутствие возможности его изменения для управления интенсивностью спектральных линий в регистрируемых спектрах снижают эфффективность использования линеек БЛПП-369М1 в САЭС из-за завышения пределов обнаружения БМ за счёт повышенного шума считывания этой линейки. Необходимо также отметить, что способ САЭС предназначен для анализа геологических порошковых проб, атомно-эмиссионные спектры которых насыщены спектральными линиями элементов. Для их лучшего разделения также требовалось повышение пространственной разрешающей способности анализатора МАЭС.

С целью повышения временной и пространственной разрешающей способности, а также чувствительности были созданы быстродействующие анализаторы МАЭС на основе двух новых линеек фотодетекторов БЛПП-2000 и БЛПП-4000 [6]. Анализаторы разработаны по схеме с параллельным считыванием и оцифровкой выходных сигналов линеек в сборке. В этом случае минимальное время базовой экспозиции анализатора МАЭС равно минимальному времени экспозиции одной линейки. В табл. 1 приведены основные параметры линеек фотодетекторов. Из таблицы видно, что линейки БЛПП-2000 и БЛПП-4000 более чувствительны в сравнении с БЛПП-369 (имеют ниже шум считывания), обладают бо́льшим быстродействием (меньше минимальное время экспозиции) и имеют низкий темновой ток. БЛПП-4000 также обладает лучшим пространственным разрешением (меньшим шагом размещения фотоячеек). Соответственно, в спектрометрах, в которых в первую очередь требуется наибольшая чувствительность, применяется линейка БЛПП-2000, а в которых требуется максимальная спектральная разрешающая способность - линейка БЛПП-4000. 
Specifications of photodetector arrays

Table 1

\begin{tabular}{|l|c|c|c|}
\hline \multicolumn{1}{|c|}{ Параметр } & Базовая БЛПП-369M1 & БЛПП-2000 & БЛПП-4000 \\
\hline \multicolumn{1}{|c|}{ Технология } & $\mathrm{n}-\mathrm{MOП}$ & ПЗС с обратной засветкой & КМОП \\
\hline Количество фотоячеек & 2612 & 2048 & 4096 \\
\hline Шаг размещения фротоячеек, мкм & 12.5 & 14 & 7 \\
\hline Высота фотоячеек, мм & 1 & 1 & 0.2 \\
\hline Спектральный диапазон, нм & $160-1100$ & $130-1100$ & $160-1100$ \\
\hline Зарядовая емкость фотоячейки, тысяч электронов & 2000 & 30 & 80 \\
\hline Шум считывания, е- & 120 & 15 & 16 \\
\hline Темновой ток, электрон/мс·пиксель & 200 & 0.4 & 0.4 \\
\hline Минимальное время экспозиции, мс & 3 & 0.6 \\
\hline
\end{tabular}

В настоящее время практически все спектрометры, выпускаемые предприятием «ВМКОптоэлектроника», оснащены анализаторами МАЭС с линейками БЛПП-2000 или БЛПП-4000. Подтверждён значительный эффект от их применения не только в САЭС геологических порошковых проб методом просыпки-вдувания, но и в искровых вакуумных спектрометрах для экспресс-анализа металлов, при регистрации спектров индуктивно связанной плазмы (ИСП) и микроволновой плазмы (МП), а также при регистрации спектров поглощения в атомно-абсорбционном спектрометре с электротермическим атомизатором и источником непрерывного спектра.
Цель настоящей работы - ознакомить специалистов с современным техническим уровнем оптических спектрометров, оснащенных анализаторами МАЭС с линейками фотодетекторов БЛПП-2000 или БЛПП-4000 и выпускаемых предприятием «ВМК-Оптоэлектроника».

\section{СПЕКТРАЛЬНЫЕ ПРИБОРЫ}

Спектральные приборы высокого разрешения построены по оптической схеме Пашена-Рунге с отражательными вогнутыми дифракционными решётками, работающими в первом порядке дифракции. Их основные характеристики приведены в

Характеристики спектральных приборов высокого разрешения

Таблица 2

Specifications of high-resolution spectral instruments

\begin{tabular}{|c|c|c|c|c|c|c|}
\hline Наименование & Гранд & Гранд-2 & Гранд-2000 & Экспресс & Гранд-Эксперт & Фаворит \\
\hline $\begin{array}{c}\text { Совместимые источники } \\
\text { возбуждения спектров }\end{array}$ & \multicolumn{4}{|c|}{$\begin{array}{c}\text { Дуговой и искровой электрический разряд на воздухе, } \\
\text { ИСП и МП плазма }\end{array}$} & \multicolumn{2}{|c|}{ Искровой разряд в аргоне } \\
\hline $\begin{array}{l}\text { Количество линеек } \\
\text { фотодетекторов }\end{array}$ & $\begin{array}{c}14+9 \\
\text { БЛПП-4000 }\end{array}$ & $\begin{array}{c}14+14 \\
\text { БЛПП-2000 или } \\
\text { БЛПП-4000 }\end{array}$ & $\begin{array}{c}(14+14)+14 \\
\text { БЛПП-4000 }\end{array}$ & $\begin{array}{c}14 \\
\text { БЛПП-4000 }\end{array}$ & $\begin{array}{c}16+14 \\
\text { БЛПП-2000 }\end{array}$ & $\begin{array}{c}13 \\
\text { БЛПП-4000 }\end{array}$ \\
\hline $\begin{array}{l}\text { Количество измерительных } \\
\text { каналов }\end{array}$ & 94208 & $\begin{array}{l}57344 \text { или } \\
114688\end{array}$ & 172032 & 57344 & 61440 & 28732 \\
\hline $\begin{array}{l}\text { Рабочий спектральный } \\
\text { диапазон, нм }\end{array}$ & $\begin{array}{l}190 \div 350 \\
385 \div 470\end{array}$ & $\begin{array}{l}190 \div 350 \\
350 \div 780\end{array}$ & $\begin{array}{l}190 \div 350 \\
350 \div 780\end{array}$ & $195 \div 405$ & $\begin{array}{l}169 \div 350 \\
350 \div 780\end{array}$ & $169 \div 350$ \\
\hline $\begin{array}{l}\text { Спектральное разрешение } \\
\text { при ширине входной щели } \\
15 \text { мкм, пм }\end{array}$ & 7 & $\begin{array}{c}12(33)^{*} \\
\text { с БЛПП-2000 } \\
7(20)^{*} \\
\text { с БЛПП-4000 }\end{array}$ & $4(20)^{*}$ & 12 & $15(40)^{*}$ & 22 \\
\hline $\begin{array}{l}\text { Обратная линейная } \\
\text { дисперсия, нм/мм }\end{array}$ & 0.4 & $0.4(1.0)^{*}$ & $0.2(1.0)^{*}$ & 0.55 & $0.4(1.0)^{*}$ & 0.55 \\
\hline $\begin{array}{l}\text { Вогнутая дифракционная } \\
\text { решётка: } \\
\text { частота штрихов, штр/мм } \\
\text { радиус кривизны, мм }\end{array}$ & $\begin{array}{c}\text { нарезная } \\
2400 \\
1000\end{array}$ & $\begin{array}{c}\text { нарезная } \\
2400(900)^{\star} \\
1000\end{array}$ & $\begin{array}{c}\text { нарезная } \\
2400 \\
2000\end{array}$ & $\begin{array}{c}\text { нарезная } \\
1800 \\
1000\end{array}$ & $\begin{array}{c}\text { нарезная } \\
2400(900)^{\star} \\
1000\end{array}$ & $\begin{array}{c}\text { голографи- } \\
\text { ческая } \\
3600 \\
498\end{array}$ \\
\hline угол падения, град. & 26.5 & $26.5(21.45)^{\star}$ & 25.5 & 20 & $28.45(21.45)^{\star}$ & 42 \\
\hline направление угла блеска, нм & 220 & $220(550)^{*}$ & 220 & 260 & $195(550)^{*}$ & 225 \\
\hline $\begin{array}{l}\text { размер заштрихованной } \\
\text { области, мм }\end{array}$ & $60 \times 50$ & $60 \times 50(66 \times 40)^{*}$ & $75 \times 75$ & $66 \times 40$ & $40 \times 30(66 \times 40)^{*}$ & диаметр 60 \\
\hline
\end{tabular}

Примечание: * - данные для длинноволнового спектрального диапазона. 
табл. 2. Можно заметить, что рабочий спектральный диапазон спектральных приборов, предназначенных для работы с источниками возбуждения проб в атмосфере воздуха, начинается с коротковолновой границы пропускания воздуха - 190 нм, а работающих с искровым разрядом в аргоне - с 169 нм, что получено вакуумированием корпусов этих приборов. Такая граница определяется необходимостью регистрации аналитических линий вакуумного ультрафиолета (ВУФ), но в случае необходимости может быть расширена до 130 нм.

Спектральные приборы «Гранд-2», «Гранд-2000» и «Гранд-Эксперт» содержат два параллельно работающих полихроматора по схеме Пашена-Рунге, один из которых регистрирует спектр в длинноволновом диапазоне 350-780 нм. Лучшее спектральное разрешение в коротковолновой области имеет прибор «Гранд-2000» за счёт использования вогнутой дифракционной решётки с частотой штрихов 2400 штр./мм с радиусом кривизны 2000 мм [7]. Обратная линейная дисперсия решётки в два раза меньше дисперсии прибора «Гранд», что даёт соответствующее уменьшение предела спектрального разрешения.

В составе спектральных приборов могут использоваться как линейки фотодетекторов БЛПП-2000, так и БЛПП-4000. В табл. 2 приведены наиболее востребованные конфигурации приборов. Минимальное время базовой экспозиции спектральных приборов на основе линеек фотодетекторов БЛПП-2000 составляет 1 мс, а на основе БЛПП-4000 - 2 мс.

Параметры различных модификаций малогабаритных спектральных приборов «Колибри-2» приведены в [8].

\section{АТОМНО-ЭМИССИОННЫЕ СПЕКТРОМЕТРЫ}

Атомно-эмиссионные спектрометры создавались на основе разработанных на предприятии спектральных приборов, путём оснащения их соответствующими источниками возбуждения спектров. Все спектрометры оснащены системой охлаждения замкнутого типа. Для защиты от перепадов температуры, света и пыли спектрометры напольного исполнения снабжены внешним теплопылезащитным корпусом. Внутри с помощью пылеулавливателя и бесшумного вентилятора создаётся избыточное давление и осуществляется вентиляция внутреннего рабочего пространства. Ниже указаны основные конфигурации производимых спектрометров.

Доступны конфигурации всех приведённых ниже спектрометров с вынесенным в защитный химический бокс источником возбуждения спектров и отдельно расположенным спектральным прибором, что необходимо, например, для анализа радиоактивных веществ.

Все спектрометры работают под управлением программного обеспечения Атом, которое непре- рывно совершенствуется, отрабатывая пожелания использующих его аналитиков и инженеров-разработчиков новых приборов [9].

Спектрометры «Гранд-Глобула» «Экспресс» с дуговым и искровым разрядом для атомно-эмиссионного анализа порошков методом испарения из канала графитового электрода, а также металлов - стационарные приборы в напольном исполнении. В комплект поставки могут быть включены станок для заточки графитовых электродов «Кратер-2М», калибратор длины (ломатель) графитовых электродов, специализированные держатели проб и другое оборудование.

Спектрометры «Гранд-Глобула» обычно создаются на основе спектрального прибора «Гранд», штатива «Глобула» и генератора «Шаровая молния».

Спектроаналитический штатив «Глобула» предназначен для возбуждения дуговых и искровых спектров эмиссии при количественном и качественном атомно-эмиссионном анализе веществ и материалов. Длительные экспозиции не требуют участия оператора в коррекции межэлектродного промежутка. Встроенные в штатив видеокамера и сервоприводы держателей электродов предназначены для автоматического поддержания межэлектродного промежутка в процессе испарения образца путём компьютерного анализа в реальном времени изображения дугового разряда, а также начальной установки этого промежутка относительно оптической оси. Электрододержатели охлаждаются водой с помощью системы охлаждения замкнутого цикла.

Спектроаналитический генератор «Шаровая молния» используется для возбуждения дугового и искрового разряда. Генератор разработан специально для использования в спектральном анализе проб сложного состава для одновременного определения примесных и легирующих компонентов в широком диапазоне концентраций. «Шаровая молния» является надёжным, высокотехнологичным и многофункциональным прибором, созданным на основе силовых IGBT-транзисторов. Встроенный микроконтроллер обеспечивает простое управление работой генератора и позволяет аналитику задавать оптимальные режимы возбуждения спектра, в том числе с изменением полярности, длительности импульсов и силы тока непосредственно в ходе одной экспозиции. Стабильность тока составляет $0.1 \%$. Последовательное включение в ходе одной экспозиции искрового и дугового режимов позволяет одновременно получить высокую сходимость для основных составляющих пробы и низкие пределы обнаружения для примесей.

С помощью спектрометров «Гранд-Глобула» реализуются множество существующих методик анализа по ГОСТ, а также разрабатываются новые МВИ, например, [10].

В базовый вариант спектрометра «Экспресс» входит одноимённый спектральный прибор, штатив «Кристалл» и генератор «Везувий-3». Существуют 
исполнения спектрометра для анализа моторного масла и смазок.

Универсальный штатив «Кристалл» удобен в работе и обслуживании: дверцы расположены с двух сторон, что упрощает технологический доступ к электрододержателям и шлангам водяного охлаждения; встроенная светодиодная подсветка электродов вдоль оптической оси позволяет проводить визуальный контроль положения электродов относительно входной щели спектрального прибора; обеспечивается точная автоматическая установка межэлектродного промежутка величиной 2, 1 или 0.1 мм. В комплект штатива входят три сменных нижних электрододержателя для установки проб в виде: металлических образцов цилиндрической (диаметр 6-60 мм) и произвольной формы, массой до 2 кг; металлических и графитовых стержней (длиной 20-150 мм и диаметром 2-12 мм); специального зажима для тонкого листового материала. Возможна установка нижнего электрододержателя от штатива УШТ-4.

Универсальный генератор «Везувий-3» обеспечивает возбуждение атомно-эмиссионных спектров металлических, порошковых проб и смазок. Поддерживает стабильность тока дуги (не более $0.5 \%$ при изменениях питающего напряжения от 150 до 250 В и величины аналитического промежутка, обеспечивая воспроизводимость результата. Производит измерение напряжения и тока дуги во время экспозиции с сохранением этих данных в специальном файле программы «Атом», что даёт дополнительную информацию разработчикам новых методик анализа. Высокий КПД при малых габаритах, контроль температуры узлов генератора обеспечивают его длительную бесперебойную работу.

Спектрометры «Гранд-Поток» с дуговым разрядом для атомно-эмиссионного экспресс-анализа порошковых проб методом просыпки-вдувания - стационарные приборы в напольном исполнении. Обычно создаются на основе спектрального прибора «Гранд» с линейками фотодетекторов БЛПП-4000 и электродуговой установки «Поток». В качестве спектрального прибора могут быть также использованы «Гранд-2», в случае необходимости регистрации спектральных линий с длиной волны больше 470 нм, или «Гранд-2000» для снижения вероятности спектральных наложений. В комплект поставки могут входить: дополнительный монитор, устройство для перемешивания порошковых проб, стол с каменной столешницей, снабженный металлической решёткой и поддоном для сбора порошка и другое оборудование. Размеры столов произвольные по согласованию с организацией-потребителем.

Электродуговая установка «Поток» предназначена для возбуждения в электрической дуге атомно-эмиссионных спектров порошковых проб методом просыпки-вдувания. Обеспечивает высокую производительность рутинных анализов, отлича- ется низким расходом графитовых электродов. В компактной моноблочной конструкции объединены электромеханические узлы транспортёрной подачи пробы и автоматической калибровки расстояния между электродами, генератор переменного тока до 40 А и модуль связи с компьютером. В состав установки входят:

- Генератор дугового разряда. Обладает высокой стабильностью работы. Система питания дугового разряда, основанная на современной полупроводниковой элементной базе, позволяет достичь высокого КПД и стабилизировать ток разряда независимо от состояния электродов и подачи пробы. Гибкая настройка работы генератора позволяет работать в режимах дуги переменного/постоянного тока, прерывистой дуги и дуги со ступенчатым током заданной полярности, с возможностью установки различной частоты, амплитуды и скважности тока; - Камера сгорания. Механизм калибровки межэлектродного промежутка и крепёж воронки на внешнем корпусе камеры сгорания обеспечивают точность подачи пробы и поддержания межэлектродного расстояния при длительной работе. Крепёж воронки устроен таким образом, чтобы её чистка или замена не приводили к дополнительной юстировке относительно межэлектродного промежутка;

- Автоматическая подача пробы, состоящая из двух независимых транспортёрных лент, позволяет регулировать поступление вещества в зону дугового разряда со скоростью в диапазоне 1-20 мг/с. Последовательная работа транспортёров позволяет увеличить скорость проведения анализа, а их одновременная работа - производить смешивание анализируемого вещества с бусером непосредственно в зоне дугового разряда;

- Дезинтегратор, входящий в конструкцию держателя воронки, позволяет ударной волной разбивать слипшиеся частицы пробы перед поступлением их в зону дуги. В результате увеличивается коэффициент использования пробы и улучшается повторяемость результатов анализа. Кроме того, сводится к нулю вероятность налипания пробы на выходе из воронки;

- Блокировки. Мониторинг состояния оборудования включает контроль: открытия камеры сгорания и крышек установки электродов; наличия вытяжной вентиляции и её стабилизации; наличия электродов; температуры генератора разряда; перегрузки генератора разряда;

- Стабилизатор вытяжной вентиляции. Регулировка величины вытяжной вентиляции позволяет установить оптимальное значение потока вытяжки, которое непрерывно стабилизируется системой обратной связи. Благодаря этому колебания воздуха вытяжной вентиляции не сказываются на результатах анализа, что в свою очередь приводит к улучшению их повторяемости.

Спектрометр «Гранд-Поток» оптимален для решения задач прямого экспресс-анализа порошковых 
Таблица 3

Пределы обнаружения спектрометра «Гранд-Поток»

Table 3

Detection limits of the Grand-Potok spectrometer

\begin{tabular}{|l|c|}
\hline \multicolumn{1}{|c|}{ Элементы } & ПО, г/т \\
\hline $\mathrm{Au}, \mathrm{Pd}$ & $<0.01^{*}$ \\
\hline $\mathrm{Ag}, \mathrm{Pt}$ & $<0.1^{*}$ \\
\hline $\mathrm{Mo}, \mathrm{Cd}, \mathrm{Rh}, \mathrm{Ru}$ & $\sim 0.1-1$ \\
\hline $\mathrm{Be}, \mathrm{Bi}, \mathrm{As}, \mathrm{B}, \mathrm{Co}, \mathrm{Cr}, \mathrm{Cu}, \mathrm{Ni}, \mathrm{Pb}, \mathrm{Sn} \mathrm{W}$, & $\sim 1-20$ \\
$\mathrm{~V}, \mathrm{Sb}, \mathrm{Ge}, \mathrm{Ga}, \mathrm{Hg}$ & $\sim 20-90$ \\
\hline $\mathrm{Li}, \mathrm{Zn}, \mathrm{Ba}$ & \\
\hline
\end{tabular}

Примечание: * - способом САЭС.

проб в геологоразведывательных лабораториях и обогатительных предприятиях, т.к. он обеспечивает высокую производительность (до 500 проб в рабочую смену) и низкую стоимость анализа. Пробоподготовка ограничивается высушиванием и истиранием образца до размера частиц 200 меш. Также спектрометр хорошо зарекомендовал себя при определении золота с концентрированием по методу спектрозолотометрии [11] и других видов анализов с возбуждением спектров по методу просыпки-вдувания [12].

Способ САЭС, реализуемый на спектрометре «Гранд-Поток», позволяет снизить пределы обнаружения благородных металлов до кларкового уровня за счёт регистрации и обработки временно́й последовательности спектров, содержащей десятки тысяч спектров, зарегистрированных со скоростью до 1000 спектров/с [13, 14]. Благородные металлы определяются с использованием зависимости интенсивности их аналитических линий от времени, которые содержат вспышки (сцинтилляции). А остальные элементы - по интегральному спектру. Пределы обнаружения спектрометра «Гранд-Поток» приведены в табл. 3.

Вакуумные спектрометры «Гранд-Эксперт» и «Фаворит» с искровым разрядом для экспресс-анализа металлов и сплавов - стационарные приборы в напольном исполнении. В комплект поставки спектрометров могут входить диско-шлифовальный станок для подготовки поверхности металлических проб, печь для очистки аргона, набор адаптеров для проб, щётки, стол для проб и другое оборудование.

Спектрометр «Гранд-Эксперт» и малогабаритный спектрометр «Фаворит» отличаются входящими в их состав одноимёнными спектральными приборами с соответствующими отличиями в рабочем спектральном диапазоне и разрешении (см. табл. 2). В остальном их состав совпадает: штатив с аргоновой продувкой, вакуумная система, искровой генератор «Шаровая молния-250A», осветительная система с возможностью очистки линзы без разгерметизации вакуумного спектрометра и блок управления элементами спектрометра. Для достижения необходимого уровня вакуума в вакуумных полихроматорах ис- пользуется высокопроизводительный малошумный безмасляный (исключает конденсацию паров масла внутри корпуса) вакуумный насос, предназначенный для круглосуточной поддержки давления остаточных газов 2-4 Па и имеющий ресурс 25000 часов, при этом при эксплуатации насос работает всего 1-2\% рабочего времени.

Аргоновый штатив позволяет работать с пробами, имеющими сечение диаметром более 14 мм. Возможен анализ проб малого размера с использованием соответствующих адаптеров, например, проволоки. Противоэлектрод штатива изготовлен из вольфрама.

Возбуждение спектра осуществляется высокостабильным генератором «Шаровая молния-250А». Генератор позволяет варьировать параметры разряда: частота импульсов от 1 Гц до 1 кГц, длительность импульсов от 20 мкс, программируемое изменение тока в процессе разряда от 20 до 250 A; а также синхронизировать импульсы разряда с регистрацией спектров анализаторами МАЭС.

Осветительная система обеспечивает высокое пропускание в рабочем диапазоне длин волн, диафрагмируя излучение, не используемое для анализа. Линза системы освещения входной щели является разделителем вакуума спектрометра и аргоновой атмосферы штатива. Очистка линзы производится без разгерметизации спектрометра.

Программное обеспечение «Атом» позволяет протоколировать показания датчиков давления в корпусе вакуумного полихроматора и расхода аргона. Средний расход аргона на получение одного спектра составляет от 1 до 2 литров, в зависимости от материала основы. С учётом увеличенного периода контроля градуировки и съемки двух параллельных измерений на пробу, стандартный 40 литровый баллон аргона сможет обеспечить проведение до 2000 определений состава рабочих проб с производительностью до 20-30 проб в час.

Спектрометры позволяют проводить определение состава металлов и сплавов на основе железа, меди, алюминия, цинка, титана, никеля, магния, золота, серебра, платины и другие по ГОСТ и МВИ [15]. Типичный диапазон измерения концентраций определяемых элементов составляет от десятых долей ррт до десятков процентов. «Гранд-Эксперт» обладает дополнительной возможностью определения неметаллических включений [16].

Спектрометры с азотной микроволновой плазмой «Гранд-СВЧ» и аргоновой индуктивно связанной плазмой «Гранд-ИСП» для атомно-эмиссионного анализа жидкостей - стационарные приборы в напольном исполнении. Они обычно создаются на основе спектрального прибора «Гранд-2» с линейками фотодетекторов БЛПП-2000. В спектрометрах реализована технология расширения динамического диапазона до 6 порядков величины за счёт попеременной регистрации спектров с двумя временами базовой 
экспозиции. В комплект поставки спектрометров могут входить автодозатор с емкостью до 4 штативов по 90 пробирок объемом 10 мл в каждом штативе, установка искрового пробоотбора «Аспект» для прямого экспресс-анализа металлических проб [3], установка электротермического испарения проб для снижения пределов обнаружения примесей и другое оборудование.

Система ввода жидкой пробы включает многоцелевую систему распыления образцов, состоящую из пневматического распылителя, одно или двухпроходной распылительной камеры и трубок перистальтического насоса, а также управляемый компьютером 3-х или 5-ти канальный перистальтический насос с переменной скоростью 0-100 об/ мин. Сочетание типов, параметров и материалов системы ввода пробы позволяет анализировать любые растворы, включая органические растворители, пробы с HF, имеющие высокий уровень солей, нерастворимых частиц.

Для управления потоками газа используются система электромагнитных клапанов с компьютерным управлением регулирования потоков: внешний газовый поток от 8 до 15 л/мин, промежуточный от 0 до 1 л/мин, поток распылителя от 0 до 1 л/мин. Имеется возможность добавления воздушного потока от 0 до 1 л/мин в промежуточный поток горелки. Для «поджига» плазмы спектрометра «Гранд-СВЧ» в горелку кратковременно вводится аргон, после чего поток аргона автоматически отключается. Отсечка «холодного хвоста» плазмы осуществляется «воздушным ножом» с расходом воздуха или азота 5 л/мин для снижения матричных влияний и предохранения входной оптики спектрометра.

Источником возбуждения спектров в спектрометрах «Гранд-СВЧ» является азотная МП [17]. В качестве генератора СВЧ энергии используется твердотельный промышленный воздушно-охлаждаемый магнетрон, работающий на частоте 2450 МГц. Мощность плазмы варьируется от 1000 до 1700 Вт с шагом 50 Вт. Возбуждение плазмы осуществляется в цилиндрическом СВЧ резонаторе с установленным внутри диэлектрическим элементом, в центре которого размещена вертикально ориентированная стандартная горелка, применяемая в ИСП спектрометрах. Получаемая в горелке плазма имеет тороидальную форму, размером близким к индуктивно-связанной плазме с высокой пространственной и временной стабильностью, а также высоким отношением «сигнал пробы / фон плазмы». Полученная МП является стабильной во времени и пространстве, что позволяет вводить в нее высокосолевые растворы без потери стабильности и без загрязнения горелки солями. В спектрометре реализован ввод излучения с аксиальным обзором плазмы.

Мониторинг состояния оборудования включает контроль: наличие в резонаторе горелки; нажатие кнопки аварийного отключения плазмы; контроль
Пределы обнаружения, мкг/л. Время интегрирования 10 секунд

Table 4

Detection limits, $\mu \mathrm{g} / \mathrm{l}$. Integration time $10 \mathrm{~s}$

\begin{tabular}{|c|c|c|}
\hline \multicolumn{1}{|c|}{ Элементы } & Гранд-СВЧ & Гранд-ИСП \\
\hline $\begin{array}{l}\mathrm{Ag}, \mathrm{B}, \mathrm{Ba}, \mathrm{Be}, \mathrm{Cr}, \mathrm{Cu}, \\
\mathrm{Mg}, \mathrm{Mn}, \mathrm{V}\end{array}$ & $<1$ & $<0.5$ \\
\hline $\mathrm{Al}, \mathrm{Cd}, \mathrm{Co}, \mathrm{Fe}, \mathrm{Ni}, \mathrm{Pb}, \mathrm{Zn}$ & $<5$ & $<1$ \\
\hline
\end{tabular}

давления и расхода газов для азота, аргона и воздуха; контроль температуры окна пре-оптики; контроль температуры источника питания, магнетрона и СВЧ-резонатора; контроль состояния плазмы.

Линейный динамический диапазон градуировочного графика достигает 5 порядков при использовании одной линии и 7 порядков при использовании двух и более линий. Долговременная стабильность сигнала не более 2 \% ОСКО без внутренней стандартизации и коррекции дрейфа сигнала. Пределы обнаружения спектрометра «Гранд-СВЧ» приведены в табл. 4.

Источником возбуждения спектров в спектрометрах «Гранд-ИСП» является высокостабильная аргоновая индуктивно связанная плазма. Для возбуждения ИСП используется плазменный генератор с рабочей частотой 40,68 МГц и водяным охлаждением. Мощность плазмы 600-2000 Вт. Стабильность $0.01 \%$. Автоматическая динамическая подстройка импеданса. Плазменный генератор обеспечивает надёжную работу плазмы на любых мощностях и типах образцов.

Наблюдение плазмы аксиальное, радиальное, двойное (с автоматическим переключением). Радиальное наблюдение рекомендуется для расширения динамического диапазона и работы с высокоминерализованными пробами, а также для снижения матричных влияний. Аксиальное наблюдение - для определения низких значений концентраций.

Мониторинг состояний оборудования включает контроль давления и расхода газов; контроль температуры источника питания, ВЧ генератора и др.; контроль состояния плазмы; контроль вытяжки.

Линейный диапазон градуировочного графика достигает 5 порядков при использовании одной линии и до 8 порядков при использовании двух линий [18]. Долговременная стабильность сигнала не более 2 \% ОСКО без внутренней стандартизации и коррекции дрейфа сигнала. Пределы обнаружения спектрометра «Гранд-ИСП» приведены в табл. 4.

Спектрометры с воздушной микроволновой плазмой «Колибри-СВЧ» и пламенные спектрометры «Павлин» для атомно-эмиссионного определения щелочных и щелочноземельных элементов в растворах - стационарные настольные приборы, в составе которых используется спектральный прибор «Колибри-2» с одной линейкой фотодетекторов БЛПП-2000. Спектрометры позволяют 
Таблица 5

Пределы обнаружения, мкг/л. Время интегрирования 10 секунд

Table 5

Detection limits, $\mu \mathrm{g} / \mathrm{l}$. Integration time $10 \mathrm{~s}$

\begin{tabular}{|c|c|c|}
\hline Элемент & Колибри-СВЧ & Павлин \\
\hline $\mathrm{K}$ & 1 & 1 \\
\hline $\mathrm{Na}$ & 0.5 & 1 \\
\hline $\mathrm{Ca}$ & 0.5 & 10 \\
\hline $\mathrm{Li}$ & 0.1 & 0.1 \\
\hline
\end{tabular}

проводить экспресс-определение широкого диапазона концентраций (до 8 порядков) натрия, лития, калия, кальция, бария, стронция, цезия, рубидия и др. элементов в технологических растворах. Пределы обнаружения ряда элементов приведены в табл. 5.

Преимуществом спектрометров с воздушной МП «Колибри-СВЧ» является отсутствие горючих газов и более низкие пределы обнаружения, а пламенного спектрометра «Павлин» - наличие аттестованных методик анализа и меньшая стоимость.

Возбуждение излучения пробы в спектрометре «Колибри-СвЧ» осуществляется в источнике МП в целом похожим на источник «Гранд-СВЧ» с идентичными газовой и пробоподающей системами, отличающимся конструктивным исполнением в виде автономного прибора с горизонтальным расположением горелки и использованием воздуха в качестве плазмообразующего газа.

Спектрометр «Павлин» для возбуждения атомной эмиссии пробы использует воздушноацетиленовое пламя. Спектрометр работает при малом расходе ацетилена, значение которого не превосходит 0.8 л/мин. Режим горения в трехщелевой горелке обеспечивает повышенную температуру пламени над центральной щелью горелки, что значительно повышает чувствительность определения, особенно кальция. Область регистрации в пламени выбирается путем перемещения горелки шаговым приводом. Рабочие давления составляют 2.5 атм. для воздуха и 0.9 атм. для ацетилена.

Система ввода пробы включает капилляр, пневматический распылитель и распылительную камеру. Распылительная камера и горелка изготовлены из химически стойкого сплава, позволяющего проводить анализ высококонцентрированных растворов в том числе литиевых. Режим очистки тракта подачи пробы обеспечивает очистку от 10 г/л до 0.0001 г/л за 2 минуты. Максимальная минерализация пробы составляет $10 \%$.

Для управления потоками газов используются система электромагнитных клапанов, датчиков давления и расходомеров. На лицевой панели прибора имеется визуальная индикация значений потоков ацетилена и воздуха. Безопасность работы прибора обеспечена рядом блокировок, срабатывающих при недостаточном давлении или расходе воздуха, при погасании пламени, а также при утечке ацетилена внутри прибора.

Излучение пробы направляется на входную щель спектрального прибора «Колибри-2» с помощью зеркально-линзового конденсора, собирающего излучение с двух сторон горелки. Яркость регистрируемого излучения пламени сбалансирована, что даёт возможность одновременно использовать для анализа спектральные линии, различающиеся по чувствительности более чем на 3 порядка [19].

\section{АТОМНО-АБСОРБЦИОННЫЕ СПЕКТРОМЕТРЫ}

Атомно-абсорбционные спектрометры "Гранд-ААС» высокого спектрального разрешения с источником непрерывного спектра и электротермическим атомизатором для одновременного определения элементов $в$ жидкости - стационарные приборы в напольном исполнении созданные на основе спектрального прибора «Гранд-2» с линейками фотодетекторов БЛПП-2000, плазменного источника непрерывного спектра и электротермического атомизатора.

На выходе полихроматора длинноволнового диапазона прибора «Гранд-2», использованного в спектрометре «Гранд-ААС», регистрация спектра осуществляется сборкой из 10-ти линеек БЛПП2000, расположенных в соответствии с положением аналитических линий абсорбции элементов. В итоге рабочий спектральный диапазон спектрометра состоит из пяти областей: 190-350, 350-593, 656-690, 754-789 и 829-855 нм. Разрешение спектрометра в области 190-350 нм составляет 12 пм, в остальных областях - 33 пм. Регистрация последовательности спектров поглощения в течении 1-2 секундного импульса электротермической атомизации пробы ведётся одновременно во всём рабочем спектральном диапазоне с временем базовой экспозиции 1 мс.

Плазменный источник непрерывного спектра, выполненный на основе лазерной дуги в ксеноне, обладает высокой яркостью, а также высокими показателями временной и пространственной стабильности. Ресурс работы источника составляет 10000 ч.

Электротермический атомизатор создан на основе графиитовой секционной печи продольного нагрева с пиропокрытием длиной 25 мм и внутренним диаметром 5 мм. Блок питания атомизатора с обратной связью по температуре печи, измеряемой встроенным быстродействующим пирометром (1000 измерений/с), позволяет осуществлять программируемый нагрев с регулируемой скоростью до $8000^{\circ} \mathrm{C} / \mathrm{c}$ на стадии атомизации. Быстрый нагрев обеспечивает максимальную амплитуду сигналов поглощения.

Дозировка жидкой пробы (5-50 мкл) в графритовую печь производится автоматическим дозатором. Автодозатор на 34 ячейки обеспечивает 
автоматизацию процесса измерений, делает его полностью автономным после задания необходимых параметров работы и составления плана измерений, что повышает производительность и точность анализа.

Мониторинг состояний оборудования включает: контроль давления и расхода аргона; наличие водяного охлаждения атомизатора; зажим графитовой кюветы.

Коррекция неселективного поглощения проводится по зарегистрированным спектрам поглощения с применением алгоритма вычисления фона, встроенного в программу [9]. После того, как убрано неселективное поглощение, вычисляется аналитический сигнал интегрированием линии по длине волны и времени. Диапазон одновременно определяемых концентраций элементов составляет до 4 порядков при пределах обнаружения до сотых долей мкг/л [20, 21].

\section{ЗАКЛЮЧЕНИЕ}

В заключение отметим, что на основе анализаторов МАЭС с новыми линейками фотодетекторов БЛПП-2000 и БЛПП-4000 разработан и освоен в производстве предприятием «ВМК-Оптоэлектроника» ряд атомно-эмиссионных спектрометров: с дуговым и искровым разрядом «Гранд-Глобула» и «Экспресс» для прямого анализа порошковых проб методом испарения из канала графитового электрода, а также металлов; с дуговым разрядом «Гранд-Поток» для экспресс-анализа порошковых проб методом просыпки-вдувания; вакуумные спектрометры с искровым разрядом в атмосфере аргона «Гранд-Эксперт» и «Фаворит» для экспресс-анализа металлов и сплавов; с азотной микроволновой плазмой «Гранд-СВЧ» и с аргоновой индуктивно связанной плазмой «Гранд-ИСП» для анализа жидкостей; с воздушной микроволновой плазмой «Колибри-СВЧ» и с фотометрией пламени «Павлин» для определения щелочных и щелочноземельных элементов в растворах. Эти спектрометры являются средством измерения массовой доли определяемых элементов состава веществ и материалов (№ 33011-11 в Госреестре средств измерения РФ, Реестре государственной системы обеспечения единства измерений Республики Казахстан за № KZ.02.03.07668-2017/33011-11, Госреестре средств измерений Республики Узбекистан под № 02.3722-18) и успешно используются в аналитических лабораториях России и стран СНГ для решения задач атомно-эмиссионного анализа.

Способность атомно-абсорбционного спектрометра «Гранд-ААС» вести одновременное определение десятков элементов в жидкости при характеристиках результатов анализа близких к одноэлементным атомно-абсорбционным спектрометрам позволяют рассчитывать на успешное внедрение этого спектрометра в аналитическую практику. Очевидно, что наиболее эффрективное применение спектрометр «Гранд-ААС» может найти при анализе проб малого объема, что важно в фармацевтике, криминалистике, а также при анализе уникальных артефактов.

\section{ЛИТЕРАТУРА}

1. Лабусов В.А., Гаранин В.Г., Шелпакова И.Р. Многоканальные анализаторы атомно-эмиссионных спектров. Современное состояние и аналитические возможности // Журнал аналитической химии. 2012. Т. 67, № 7. С. 697-707. 2. Путьмаков А.Н., Попов В.И., Лабусов В.А., Борисов А.В. Новые возможности модернизированных спектральных приборов // Заводская лаборатория. Диагностика материалов. 2007. T. 73, № S. C. 26-28

3. Лабусов В.А., Гаранин В.Г., Зарубин И.А. Новые спектральные комплексы на основе анализаторов МАЭС // Заводская лаборатория. Диагностика материалов. 2017. T. 83, № 1, часть II. С. 15-20.

4. Бабин С.А., Лабусов В.А. Оценка оптимальных параметров многоэлементных твердотельных детекторов для сцинтилляционного атомно-эмиссионного спектрального анализа // Аналитика и контроль. 2014. Т. 18, № 1. С. 40-49.

5. Дзюба А.А., Лабусов В.А., Бабин С.А. Оптимизация базовой экспозиции твердотельного детектора излучения в сцинтилляционном атомно-эмиссионном спектральном анализе // Аналитика и контроль. 2015. Т. 19, № 1. С. 6-12. 6. Бабин С.А., Селюнин Д.О., Лабусов В.А. Быстродействующие анализаторы МАЭС на основе линеек фотодетекторов БЛПП-2000 и БЛПП-4000 // Заводская лаборатория. Диагностика материалов. 2019. Т. 85. № 1 , часть II. С. 96-102.

7. Дзюба А.А., Лабусов В.А., Зарубин И.А. Аналитические возможности спектрометра высокого разрешения «Гранд-2000» в дуговом атомно-эмиссионном анализе // Аналитика и контроль. 2021. Т. 25, № 4. С. 331-339. 8. Зарубин И.А., Лабусов В.А., Бабин С.А. Характеристики малогабаритных спектрометров с дифракционными решетками разных типов // Заводская лаборатория. Диагностика материалов. 2019. Т. 85. № 1, часть II. С. 117-121. 9. Программное обеспечение атомного спектрального анализа «Атом» / В.Г. Гаранин [и др.] // Заводская лаборатория. Диагностика материалов. 2019. Т. 85. № 1, часть II. С. 103-111.

10. Барановская В.Б., Кошель Е.С. Дуговой атомноэмиссионный анализ редкоземельных металлов и их оксидов. М.: Техносфера, 2020. 132 с.

11. Методика НСАМ 140-С «Золото. Методика химико-спектрального анализа. Определение золота в горных породах, рудах, почвах и минералах эмиссионным спектральным методом после сорбции золота на угле», номер в реестре ФР.1.31.2012.12999, номер свидетельства об аттестации 140-01.00115-08-2012 от 18.06.2012. 12. Стандарт предприятия СТП ИГХ-020-2019 «Методика измерений массовых долей элементов в порошках органоминеральных проб методом атомно-эмиссионной спектрометрии с непрерывным введением вещества в плазму дугового разряда и интегральной регистрацией спектров фотодиодными линейками», номер в реестре ФР.1.31.2020.36185, номер свидетельства об аттестации 253.0234/RA.RU.311866/2019 от 15.11.2019. 13. Аналитические возможности спектрального комплекса «Гранд-Поток» при сцинтилляционном определении содержания золота и серебра в геологических пробах / А.А. Дзюба [и др.] // Аналитика и контроль, 2017, т. 21, № 1. C. 6-15. 
14. Дзюба А.А., Лабусов В.А., Бабин С.А. Анализаторы МАЭС с линейками фотодетекторов БЛПП-2000 и БЛПП4000 в сцинтилляционной атомно-эмиссионной спектрометрии // Аналитика и контроль. 2019. Т. 23, № 1. С. 35-42. 15. Куропятник И.Н. Стабильность результатов определения элементного состава сталей во времени при использовании вакуумного атомно-эмиссионного спектрометра «Гранд-Эксперт» // Заводская лаборатория. Диагностика материалов. 2019. Т. 85. № 1, часть II. С. 135-138. 16. Бокк Д.Н., Лабусов В.А. Определение неметаллических включений в металлических сплавах методом атомно-эмиссионной спектрометрии с искровым возбуждением (обзор) // Заводская лаборатория. Диагностика материалов. 2018. Т. 84, № 12. С. 5-19.

17. Пелипасов О.В., Лабусов В.А., Путьмаков А.Н. Атомно-эмиссионные спектрометры с азотной микроволновой плазмой. Новосибирск.: Изд-во НГТУ, 2021. 211 с.

18. Аналитические возможности спектрометра «Гранд» при анализе растворов с использованием индуктивносвязанной плазмы / О.В. Пелипасов [и др.] // Заводская лаборатория. Диагностика материалов. 2019. Т. 85. № 1, часть II. C. 82-85.

19. Расширение рабочего диапазона определения щелочных металлов и кальция методом пламенной фотометрии со спектрометром «Павлин» / И.А. Зарубин [и др.] // Аналитика и контроль. 2021. Т. 25, № 4. С. 326-330. 20. Атомно-абсорбционный спектрометр высокого разрешения для одновременного многоэлементного анализа / В.А. Лабусов [и др.] // Аналитика и контроль. 2018. Т. 22, № 4. C. 451-457.

21. High-resolution continuum-source electrothermal atomic absorption spectrometer for simultaneous multi-element determination in the spectral range of $190-780 \mathrm{~nm} /$ V.A. Labusov [et al.] // J. Anal. At. Spectrom. 2019. 34. P.1005-1010.

\section{REFERENCES}

1. Labusov, V.A., Garanin, V.G. \& Shelpakova, I.R. Multichannel analyzers of atomic emission spectra: Current state and analytical potentials. J. Anal. Chem., 2012, vol. 67, pp. 632641. https://doi.org/10.1134/S1061934812070040

2. Putmakov A.N., Popov V.I., Labusov V.A., Borisov A.V. [New possibilities of modernized spectral instruments]. Zavodskaia laboratoriia. Diagnostika materialov [Industrial laboratory. Diagnostics of Materials], 2007, vol. 73, no. S, pp. 26-28 (in Russian).

3. Labusov, V.A., Garanin, V.G. \& Zarubin I.A. New Spectral Complexes Based on MAES Analyzers. Inorganic Materials, 2018, vol. 54, no. 14, pp. 1443-1448. DOI: 10.1134/ S0020168518140133

4. Babin S.A., Labusov V.A. [Estimation of the Optimal Parameters of Multielement Solid-State Detectors for Atomic Emission Spectral Scintillation Analysis]. Analitika i kontrol' [Analytics and Control], 2014, vol. 18, no. 1, pp. 40-49 (in Russian). http://dx.doi.org/10.15826/analitika.2014.18.1.004 5. Dzyuba A.A., Labusov V.A., Babin S.A. [Basic exposure time optimization of a solid-state radiation detector in scintillation atomic emission spectrometry]. Analitika i kontrol' [Analytics and Contro/], 2015, vol. 19, no. 1, pp. 6-12 (in Russian). http:// dx.doi.org/10.15826/analitika.2015.19.1.005

6. Babin S.A., Selyunin, D.O. \& Labusov, V.A. High-Speed Multichannel MAES Analyzers Based on BLPP-2000 and BLPP-4000 Photodetector Arrays. Inorganic Materials, 2020, vol. 56, no. 14, pp. 1431-1435. https://doi.org/10.1134/ S0020168520140022
7. Dzyuba A.A., Dodonov S.V., Labusov V.A. [Analytical capabilities of the Grand-2000 high-resolution spectrometer]. Analitika i kontrol' [Analytics and Control], 2021, vol. 25, no. 4, pp. pp. 331-339 (in Russian).

8. Zarubin I.A., Labusov V.A. \& Babin S.A. Characteristics of Compact Spectrometers with Diffraction Gratings of Different Types. Inorganic Materials, 2020, vol. 56, no. 14, pp. 1436 1440. https://doi.org/10.1134/S0020168520140162

9. Garanin V.G., Neklyudov O.A., Petrochenko D.V., Semenov Z.V., Pankratov S.V., Vashchenko P.V. [«Atom» software for atomic spectral analysis]. Zavodskaia laboratoriia. Diagnostika materialov [Industrial laboratory. Diagnostics of Materials], 2019, vol. 85, no. 1, Part II, pp. 103-111 (in Russian). https:// doi.org/10.26896/1028-6861-2019-85-1-II-103-111

10. Baranovskaya V.B., Koshel E.S. Dugovoi atomnoemissionniy analiz redkozemel'nykh metallov i ikh oksidov [Arc atomic emission analysis of rare earth metals and their oxides]. Moscow, Technosphere, 2020. 132 p. (in Russian). 11. Methodology NSAM 140-C Zoloto. Metodika khimikospektral'nogo analiza. Opredelenie zolota v gornykh porodakh, rudakh, pochvakh i mineralakh emissionnym spektral'nym metodom posle sorbtsii zolota na ugle [Gold. Chemical spectral analysis technique. Determination of gold in rocks, ores, soils and minerals by the emission spectral method after sorption of gold on coal]. Register number FR.1.31.2012.12999, attestation certificate number 140-01.00115-08-2012 dated 18.06.2012. 12. Enterprise standard STP IGKh-020-2019. Metodika izmerenii massovykh dolei elementov $v$ poroshkakh organomineral'nykh prob metodom atomno-emissionnoi spektrometrii s nepreryvnym vvedeniem veshchestva v plazmu dugovogo razriada i integral'noi registratsiei spektrov fotodiodnymi lineikami [Methodology for measuring the mass fractions of elements in powders of organomineral samples by atomic emission spectrometry with continuous introduction of a substance into the arc discharge plasma and integral registration of spectra with photodiode rulers]. Registry number FR.1.31.2020.36185, attestation certificate number 253.0234 / RA.RU.311866 / 2019 dated 15.11.2019.

13. Dzyuba A.A., Labusov V.A., Vasil'eva I.E., Shabanova E.V., Babin S.A. [Analytical capabilities of "Grand-Potok" spectral system for the scintillation determination of gold and silver in geological samples]. Analitika i kontrol' [Analytics and Control], 2017, vol. 21, no. 1, pp. 6-15 (in Russian). http:// dx.doi.org/10.15826/analitika.2017.21.1.001

14. Dzyuba A.A., Labusov V.A., Babin S.A. [Testing of MAES analyzers with BLPP-2000 and BLPP-4000 photodetector linear arrays in a "Grand-Potok" spectral system]. Analitika $i$ kontrol' [Analytics and Control], 2019, vol. 23, no. 1, pp. 35-42. (in Russian). http://dx.doi.org/10.15826/analitika.2019.23.1.005 15. Kuropyatnik I.N. [Long-term stability of measurements of the elemental composition of steel using a vacuum atomic emission spectrometer «Grand-Expert»]. Zavodskaia laboratoriia. Diagnostika materialov [Industrial laboratory. Diagnostics of Materials], 2019, vol. 85, no. 1, Part II, pp. 135-138. (in Russian). https://doi.org/10.26896/1028-6861-2019-85-1II-135-138

16. Bock D.N. \& Labusov, V.A. Determination of Nonmetallic Inclusions in Metal Alloys by the Method of Spark Atomic Emission Spectroscopy (Review). Inorganic Materials, 2019, vol. 55, pp. 1415-1427. https://doi.org/10.1134/S0020168519140012 17. Pelipasov O.V., Labusov V.A., Putmakov A.N. Atomnoemissionnye spektrometry s azotnoi mikrovolnovoi plazmoi [Atomic emission spectrometers with nitrogen microwave plasma]. Novosibirsk, Publishing house of NSTU, 2021. 211 p. (in Russian). 
18. Pelipasov O.V., Lokhtin R.A., Labusov V.A. \& Pelevina N.G. Analytical Capabilities of a Grand Spectrometer in Analysis of Solutions Using Inductively Coupled Plasma. Inorganic Materials, 2020, vol. 56, no. 14, pp. 1446-1449. https://doi. org/10.1134/S0020168520140113

19. Zarubin I.A., Putmakov A.N., Lukina E.A., Selunin D.O., Burumov I.D. [Extending the working range for the flame photometric determination of alkali metals and calcium using the Pavlin spectrometer]. Analitika i kontrol' [Analytics and Control], 2021, vol. 25, no. 4, pp. 326-330 (in Russian).

20. Labusov V.A., Boldova S.S., Selyunin D.O., Skorobogatov D.N., Saushkin M.S., Zarubin I.A., Bokk D.N., Semenov Z.V.,
Neklyudov O.A., Vashchenko P.V. [High-resolution atomic absorption spectrometer for the simultaneous multielement analysis]. Analitika i kontrol' [Analytics and Control], 2018, vol. 22, no. 4, pp. 451-457. (in Russian). http://dx.doi.org/10.15826/ analitika.2018.22.4.003

21. Labusov V.A., Boldova S.S., Selyunin D.O., Semenov Z.V., Vashchenko, P.V. \& Babin, S.A. High-resolution continuumsource electrothermal atomic absorption spectrometer for simultaneous multi-element determination in the spectral range of 190-780 nm. J. Anal. At. Spectrom., 2019, vol. 34, pp. 1005-1010. https://doi.org/10.1039/c8ja00432c 